\title{
Reproduction of Soybean Cyst Nematode on Dry Bean Cultivars Over Multiple Generations
}

Susilo H. Pormarto and Berlin D. Nelson, Department of Plant Pathology, and Ted C. Helms, Department of Plant Sciences, North Dakota State University, Fargo 58108

\begin{abstract}
Pormarto, S. H., Nelson, B. D., and Helms, T. C. 2011. Reproduction of soybean cyst nematode on dry bean cultivars over multiple generations. Plant Dis. 95:1239-1243.

Phaseolus vulgaris is a host of soybean cyst nematode (SCN; Heterodera glycines), a pathogen recently introduced into the major dry bean production area of North Dakota and northern Minnesota. The nematode reproduces less on most bean classes compared with soybean but can reduce plant growth and seed yield. An important question is the following: will SCN adapt to dry bean and, over time, increase in ability to reproduce on roots? To answer this question, the following experiments were conducted with cultivars from three bean classes. The cultivars 'Premiere' and 'Cirrus' (navy), 'Buster' and 'Othello' (pinto), and 'Eclipse' and 'Jaguar' (black) were grown in "Cone-tainers" in sand in plastic pots immersed in a water bath at $27^{\circ} \mathrm{C}$ in the greenhouse. Seedlings were inoculated with 2,000 eggs per plant

of SCN HG 0 and cysts were harvested and counted after 40 days. The eggs were immediately extracted from those cysts and seedlings were inoculated again and grown for 40 days using the same methods. Soybean 'Lee 74' was used as a control. A female index (number of cysts produced on the test plant divided by the number of cysts produced on Lee 74) was calculated for each bean cultivar after each period of 40 days. This procedure was repeated until eight generations of eggs were completed and then the experiment was repeated. There was no significant $(P \leq 0.05)$ change over time in the female index on the six bean cultivars. Therefore, there was no evidence that SCN HG 0 was increasing reproduction on dry bean cultivars during two 11-month periods of continual reproduction of $\mathrm{HG} 0$ on roots.
\end{abstract}

North Dakota and northern Minnesota produce 35\% of the dry edible bean (Phaseolus vulgaris L.) crop in the United States, with a total production of 398 million $\mathrm{kg}$ and a value of \$309 million in 2009 (21). Dry bean crops are planted in rotation with other row crops or small grains. Dry bean plants are a host of soybean cyst nematode (SCN; Heterodera glycines Ichinohe), with different bean classes showing varying degrees of suitability for SCN reproduction (24). SCN was reported on soybean (Glycine max (L.) Merr.) in North Dakota in 2003 (5) in the southeast corner of the state and is now close to moving into the major United States dry bean production area of North Dakota, which is centered in the Red River Valley. The nematode was also recently discovered in several counties close to bean production areas in northern Minnesota. At the present time, only SCN HG type 0 (HG 0) has been found in this northern soybean production area. SCN recently was demonstrated to cause a yield loss in dry bean under field conditions (25). SCN, therefore, is a potential threat to the dry bean industry in this region.

Since SCN was first reported in the United States in 1955 in North Carolina (36), this nematode has shown great ability to adapt to resistant soybean cultivars. Within a few years of using resistant cultivars, genetic variants among field isolates were discovered in many states $(19,28,29)$. There is substantial genetic diversity in $H$. glycines. In early research to classify SCN populations based on soybean compatibility, a race scheme was developed and numerous races identified (6,27). More recently, Niblack et al. (23) proposed the HG type test to better describe the population variation and create a more flexible classification system. Our knowledge of genetic variation concerning pathogenicity in $\mathrm{SCN}$ has come from research on soybean, not other crops.

Corresponding author: B. D. Nelson,

E-mail: Berlin.Nelson@ndsu.edu

Accepted for publication 7 April 2011.

doi:10.1094/PDIS-11-10-0863

(C) 2011 The American Phytopathological Society
The population dynamics of SCN have been studied extensively on soybean and shown to be a function of population densities in the field at planting and the developmental and reproductive potentials of the nematode. They are influenced by numerous biotic and abiotic factors such as temperature $(1,9)$; soil characteristics such as soil type, texture, and $\mathrm{pH}(11,34)$; soil microorganisms (17); host susceptibility $(10,26)$; population densities $(3,18,33)$; and management practices such as cropping systems and applications of pesticides and fertilizers $(4,12-14,30,32)$.

Growing resistant soybean cultivars in the presence of an SCN population is one important factor in population dynamics. Many studies have shown that the nature of soybean resistance can influence the index of parasitism (the number of females developing on a resistant soybean cultivar expressed as a percentage of those developing on a standard susceptible cultivar) of the SCN population. For example, Elliot et al. (7) reported that continuous cropping of the resistant soybean 'Bedford' on an SCN population resulted in increased reproduction on Bedford relative to the susceptible 'Essex'. Anand et al. (2) demonstrated that the SCN population selected on plant introduction (PI) 88788 developed better on 'Forrest', PI 87631-1, 'Cloud', PI 209332, and PI 88788 than on PI 89772 and PI 90763 . On the other hand, populations selected on PI 89772 and PI 90763 developed very little on PI 88788 and PI 209332. Furthermore, Young (38) showed that the ability of four subpopulations to reproduce on four soybean lines was reversed by changing the soybean line used as a host during a second cycle of selection.

SCN is most common in soybean but not dry bean production areas; thus, there has been limited opportunity for the nematode population to interact with dry bean cultivars. Indeed, in North Dakota, we have not yet found SCN infecting dry bean in a commercial production field. As SCN infests fields in dry bean production areas, the dynamics of the population may be impacted by this legume host. Compared with the susceptible soybean 'Lee 74', the nematode reproduces less on pinto, navy, and black bean cultivars grown in this area (24). For example, female indices for pinto, navy and black bean cultivars vary between 27 and 52, 23 and 66, and 5 and 22, respectively. Therefore, some cultivars would be considered resistant to moderately resistant according to the Nib- 
lack or Schmitt-Shannon criteria $(22,31)$ used to rate resistance in soybean. A system to rate dry bean for resistance to SCN has not yet been developed.

Because SCN can reduce dry bean yields (25), we are preparing for the potential impact of SCN on dry bean production. An important question that needs to be answered is "will there be a shift in the SCN population toward greater ability to reproduce on dry bean once there is continued cultivation of dry bean cultivars in infested fields?" Based on past research in soybean, our hypothesis was that, over multiple generations, SCN would adapt toward greater reproduction on dry bean. This research was performed to determine whether continuous growth of dry bean cultivars in a population of SCN HG 0 would select for biotypes more efficient in reproducing on dry bean.

\section{Materials and Methods}

Dry bean cultivars. Six cultivars representing three dry bean classes were used to study the reproduction of soybean cyst nematode on dry bean cultivars over multiple generations. 'Premiere' and 'Cirrus' (navy), 'Buster' and 'Othello' (pinto), and 'Eclipse' and 'Jaguar' (black) were chosen because they had the lowest SCN reproduction in their bean class (24). Soybean Lee-74 and 'Barnes' were used as the susceptible soybean checks to ensure that experiments for each generation had sufficient SCN reproduction for an adequate test, and for comparisons needed to obtain female indices of reproduction.

Planting, egg sources, and inoculation. The plant growth system and inoculation method were described previously (24). Following surface disinfection with $1.0 \% \mathrm{NaOCl}$ and a water rinse, seed were germinated on seed germination paper for 3 days. Uniformly healthy seedlings were transplanted into individual plastic "Cone-tainers" (type SC10 Super Cell) containing autoclaved river sand, then inoculated with eggs. The Cone-tainers were placed in autoclaved sand in plastic pots, $30.5 \mathrm{~cm}$ in diameter by $30.5 \mathrm{~cm}$ deep (Cambro, Huntington Beach, CA), and immersed in a water bath at $27 \pm 3^{\circ} \mathrm{C}$ in a greenhouse. Plants received both natural and supplemental light using high-pressure sodium lamps $\left(1,000 \mu \mathrm{E} \mathrm{m}{ }^{-2}\right.$ $\mathrm{s}^{-1}$ ) for $16 \mathrm{~h} /$ day. Following planting, plants were watered daily to field capacity and fertilized at 14 and 21 days with $3 \mathrm{ml}$ of a solution of Peters Hydro-Sol 5-11-26 (rate of $20 \mathrm{ml}$ of Peters in $980 \mathrm{ml}$ of water; W.R. Grace \& Co.-Conn., Fogelsville, PA).

Soil naturally infested with SCN was collected from a soybean field in Richland County, North Dakota in 2006. This was one of the first North Dakota fields with SCN identified in 2003. The population of SCN was identified as HG 0 (24) following the methods of Niblack et al. (23). The general methods of Niblack at al. (23) to inoculate plants were followed, with some modifications (24). Immediately after the seedling was transplanted into the sand, it was inoculated with 2,000 eggs in $2 \mathrm{ml}$ of distilled water; then, the seedling was covered with $15 \mathrm{~mm}$ of sand. The temperature of the sand in the Cone-tainers was recorded with WatchDog 450 Data loggers. Temperatures in the sand among experiments averaged $27 \pm 1^{\circ} \mathrm{C}$ but temperature variations of $3^{\circ} \mathrm{C}$ were recorded almost daily.

Females were harvested from roots 40 days following inoculation. The females were washed off the roots using pressurized tap water and collected on a 60 -mesh $(250-\mu \mathrm{m})$ sieve. Females from each plant were counted with a dissecting microscope. To ensure that mature females were removed, roots were examined with a dissecting microscope. The freshly produced eggs were immediately extracted from those females and a distilled water suspension of eggs at $1,000 \mathrm{eggs} / \mathrm{ml}$ was prepared and immediately used to inoculate newly germinated seed with 2,000 eggs each. The same procedure was repeated until eight generations of eggs were completed. To ensure that sufficient eggs were produced during each generation of eggs, additional plants were inoculated for each 40day growth cycle. A female index (FI) (22) $(\mathrm{FI}=$ a average number of females on the test plant/average number of females on the susceptible soybean Lee 74$] \times 100$ ) was calculated to measure reproduction of SCN on dry bean.

Experimental design and analysis. The experiment design was a split plot with bean classes as main plots and cultivars as subplots. The experiment used four replications and was repeated once. Transforming the data with $\log _{10}$ did not improve the pattern of the residuals; thus, the nontransformed data were used in the analysis. Data were combined over experiments and analyzed with analysis of variance using the Statistical Analysis System (SAS Institute, Cary, NC). Mean squares were equated to expected mean squares so that the proper $F$ tests were used for each source of variation that was tested for statistical significance. Standard deviations were produced for all data shown in graphs.

\section{Results}

SCN reproduction on susceptible soybean. SCN reproduced well on the two susceptible soybean checks, Lee-74 and Barnes, throughout all the experiments. The number of females/generation ranged between 305 and 793 and 271 and 759, with averages of 545 and 532 for Lee-74 and Barnes, respectively (Fig. 1). There were no significant differences in $\mathrm{SCN}$ reproduction over time for either susceptible soybean control. SCN produced significantly $(P$ $<0.001)$ greater numbers of females on soybean than on dry bean (data not shown, but can be interpreted from FIs in Figure 2).

SCN reproduction on dry bean. Because the objective of the research was to determine whether continuous growth of dry bean cultivars in a population of SCN would select for biotypes more efficient in reproducing on dry bean, we excluded the data of SCN

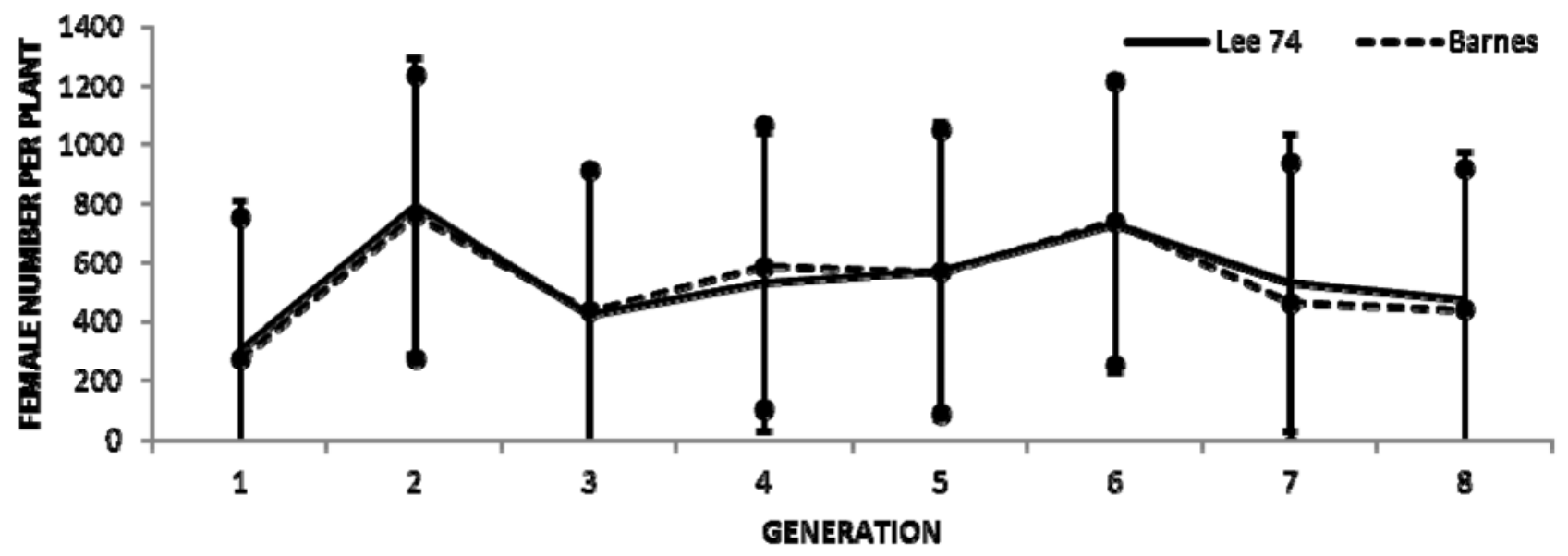

Fig. 1. Average number of soybean cyst nematode (SCN) females produced on 'Lee 74' and 'Barnes' soybean over eight generations. These are control cultivars to determine reliability of inoculation with SCN. Lee 74 is the standard used to determine the female index for other cultivars. Germinated seed were inoculated with HG 0 at 2,000 eggs/seedling and plants were grown in sand at $27 \pm 3^{\circ} \mathrm{C}$ for 40 days. Females were washed off roots and counted, eggs were extracted, and new seedlings were inoculated; this procedure was repeated eight times. Data shown were the averages of two experiments. Bars represent standard deviation of the means. 
reproduction on Lee-74 and Barnes soybean cultivars in the statistical analysis (Table 1). The FIs for SCN reproduction on dry bean cultivars over eight generations are shown in Figure 2. There were no significant differences in reproduction as measured by FI between the experiments, among the three bean classes (pinto, navy, and black bean), and between cultivars within bean classes (Table 1). Although the FIs for each cultivar did vary over time (Fig. 2), there were no significant $(P<0.05)$ differences among the eight generations for each dry bean cultivar (Table 1). Also, the bean class-generation and bean class-cultivar-generation interactions were not significant.

\section{Discussion}

We used Lee-74, a widely used susceptible soybean check (23), and Barnes, a local susceptible soybean, as susceptible checks because there currently is no dry bean cultivar that is an accepted standard susceptible check for studies of SCN on dry bean. Lee-74 is considered a reliable soybean check for various reasons. For
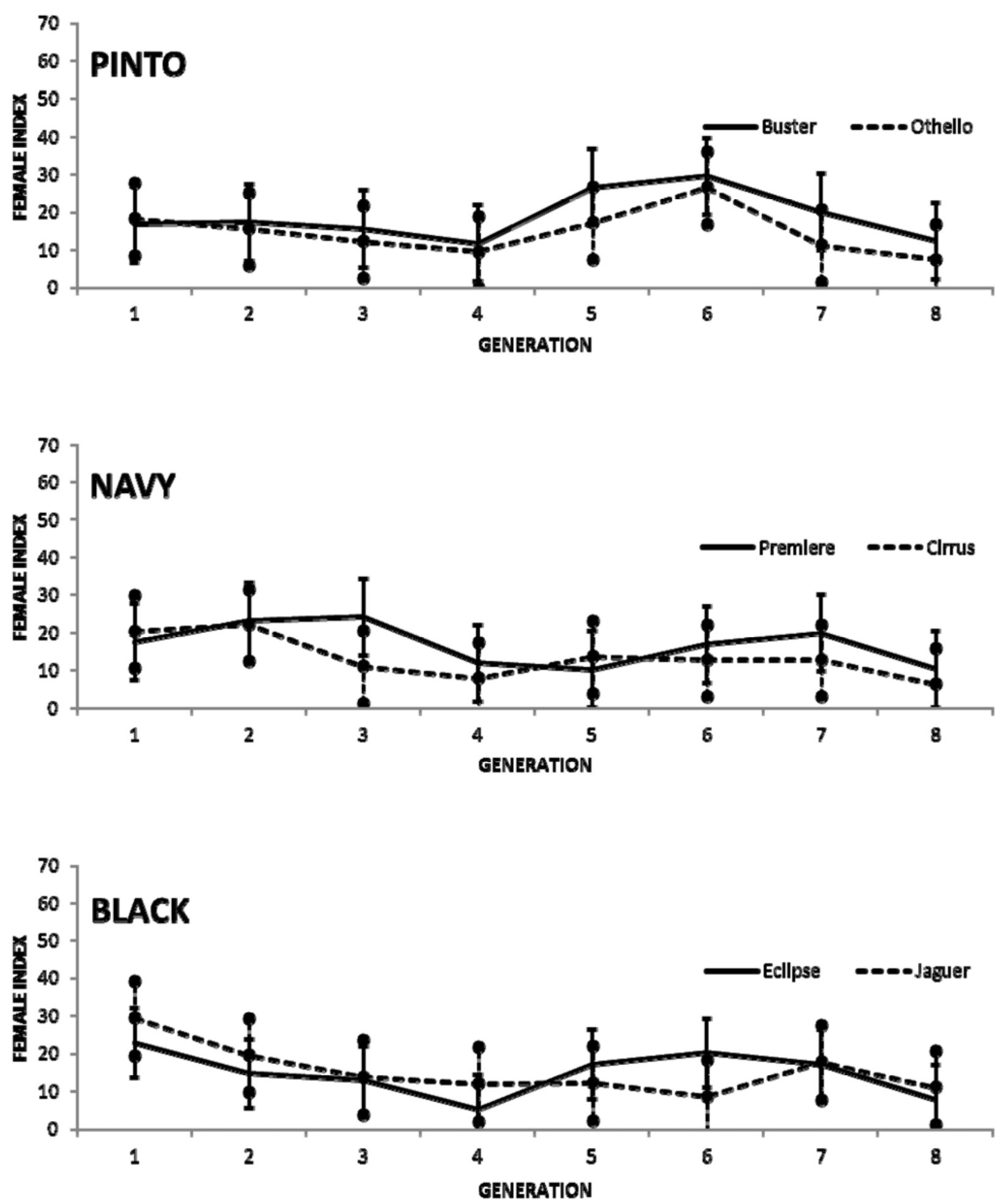

Fig. 2. Reproduction of soybean cyst nematode on dry bean cultivars in three bean classes (pinto, navy, and black) over eight generations as measured by female index (FI). $\mathrm{FI}=$ (average number of females on the test plant/average number of females on the susceptible soybean 'Lee 74 ') $\times 100$. Germinated seed were inoculated with HG 0 at 2,000 eggs/seedling and plants were grown in sand at $27 \pm 3^{\circ} \mathrm{C}$ for 40 days. Females were washed off roots and counted, eggs were extracted, and new seedlings were inoculated; this procedure was repeated eight times. Data shown were the averages of two experiments. Bars represent standard deviation of the means. 
Table 1. Summary of the analysis of variance of soybean cyst nematode reproduction over eight generations on cultivars of dry bean ${ }^{\mathrm{a}}$

\begin{tabular}{lrrr}
\hline Source & df & MSE & $\boldsymbol{F}$ value \\
\hline Experiment & 1 & 24.76 & 0.29 \\
Bean classes & 2 & 119.13 & 0.25 \\
Cultivar (bean classes) & 3 & 305.05 & 3.35 \\
Generation & 7 & 865.46 & 2.21 \\
Bean classes $\times$ generation & 14 & 275.72 & 1.49 \\
Bean classes $\times$ cultivar $\times$ generation & 21 & 109.83 & 0.17 \\
\hline
\end{tabular}

a Plants were inoculated with soybean cyst nematode $\mathrm{HG} 0$ and grown in sand for 40 days at $27 \pm 3^{\circ} \mathrm{C}$. Reproduction was measured as the number of females on the roots after 40 days. Females were washed off roots and counted, eggs were extracted, and new seedlings were inoculated; this procedure was repeated eight times. Data analyzed were the averages of two experiments.

example, reproduction of race 4 of SCN on Lee, 'Pickett', and 'Peking' soybean remained relatively constant when the nematodes were maintained on Lee soybean $(23,26)$. Triantaphyllou (35) showed that the index of parasitism on Peking soybean remained unchanged following propagation of a field population of SCN for seven consecutive generations on Lee soybean. In this current study, on neither of the susceptible checks was there an increase in SCN reproduction over the eight generations. It is also important to point out that, in each of the inoculations over the two experiments, the mean number of females on each cultivar exceeded 200, indicating that the environmental conditions for the test were favorable for infection and SCN reproduction.

One surprising result of the study was that the FIs of the two black bean cultivars were not significantly different from those of the pinto and navy bean cultivars. Averaged over the eight generations and two experiments, the average combined FI of the two black cultivars was 16 while the average combined FIs for pinto and navy bean were 17 and 15, respectively. In previous evaluations of the resistance of dry bean cultivars using methods similar to those used in this study (24), the two black bean cultivars had an average FI of 11 while the two pinto and navy cultivars had FIs of 30 and 24, respectively. The reasons for the differences in FI between these two separate studies are unknown. The lack of a bean class-generation interaction showed that none of the bean classes had altered the reproduction of SCN over time.

Our original hypothesis, based on past research on soybean, was that SCN would increase in ability to reproduce on resistant to moderately resistant dry bean cultivars over consecutive plantings. An increase in the ability of SCN to reproduce following continuous planting of resistant soybean cultivars has been shown in greenhouse experiments $(2,15,35-37)$ and in fields infested with SCN $(8,38-40)$. An increase in the reproduction of SCN race 3 (which is similar to HG 0) (23) was recorded when Pickett or Peking, two resistant soybean cultivars, were the hosts for two or more consecutive inoculations but there was no increase on the susceptible Lee when there were five continuous inoculations (26). A similar phenomenon was also reported for SCN races 1, 2, and 4 (26). Triantaphyllou (35) demonstrated an increasing index of parasitism from 2.8 to 74 for an SCN field population on the resistant Peking after seven consecutive generations. In that same study, an increased index of parasitism from 16 to 85 after five generations of selection on the resistant PI 88788 soybean was also shown. The specific population of SCN can affect the outcome of such studies. Propagation of a population from a field in North Carolina for five consecutive generations on Pickett increased the index of parasitism from 22 to 73 but, when that final population was tested on the resistant PI 88788, there was no change in the index of parasitism on PI 88788 (35). Conversely, propagation of the same beginning population for five generations on PI 88788 increased the index of parasitism of the population on PI 88788 from 4.8 to 40 but, when that final population was tested on Pickett, there was no change in the index of parasitism on Pickett. This past information about increasing reproduction over time on resistant soybean cultivars by different populations of SCN was the reason for conducting this current research with dry bean.

The data from this study, however, do not support our previous hypothesis. There are at least three reasons to explain the lack of increasing FI on dry bean in this study. First, the original source of the SCN eggs was from one population taken from a $1,500-\mathrm{ft}^{2}$ area in an infested field. The population selected may have had a narrow genetic base and lacked the ability to adapt to those dry bean cultivars. However, in general, SCN populations are heterogeneous and, within a population, there are genotypes that differ in their ability to reproduce on plant hosts. Miller (20) found that progeny of single cysts from different parts of one field produced variable numbers of females on both resistant and susceptible soybean cultivars. Another explanation is that this experiment used only HG 0. HG 0 is the least virulent type on soybean (23); however, virulence on soybean may or may not have any bearing on the ability to reproduce on dry bean. It is important to note that there are regions of synteny between the genomes of soybean and dry bean (16); thus, there could be a similar genetic basis for resistance to SCN in the two crops. Therefore, he outcome of this experiment using different HG types should be examined. Third, the cultivars of dry bean used in this experiment have FIs greater than 10. In soybean, such FIs would indicate a resistance level that is less than highly resistant. Possibly, the selection pressure needed to demonstrate an adaptation toward greater reproduction to dry bean over the time period in this study would be a highly resistant dry bean cultivar.

The most important outcome of this research was that, over time, there was no increase in SCN reproduction, indicating that this HG 0 population was not adapting toward increased ability to reproduce on dry bean. There are practical implications of this research if these results hold true for other populations of HG 0 in this area. It would appear that there will not be a rapid increase in the adaptation of SCN toward increased reproduction on some of the dry bean cultivars grown in the area. However, because this will be a new disease for dry bean growers, a prudent approach to disease management would be to monitor changes in the ability of field populations of SCN to reproduce on dry bean cultivars grown in this region.

\section{Literature Cited}

1. Alston, D. G., and Schmitt, D. P. 1988. Development of Heterodera glycines life stages as influenced by temperature. J. Nematol. 20:366-372.

2. Anand, S. C., and Brar, G. S. 1983. Response of soybean lines to differentially selected cultures of soybean cyst nematode Heterodera glycines Inhinohe. J. Nematol. 15:120-123.

3. Bonner, M. J., and Schmitt, D. P. 1985. Population dynamics of Heterodera glycines life stages on soybean. J. Nematol. 17:153-158.

4. Bostian, A. L., Schmitt, D. P., and Barker, K. R. 1986. Population changes of Heterodera glycines and soybean yields resulting from soil treatment with Alachlor, Fenamiphos, and Ethoprop. J. Nematol. 18:458-463.

5. Bradley, C. D., Biller, C. R., and Nelson, B. D. 2004. First report of soybean cyst nematode (Heterodera glycines) on soybean in North Dakota. Plant Dis. 88:1287.

6. Dong, K. 1996. Genetics and molecular aspects of Heterodera glycinessoybean interactions. Ph.D. dissertation, North Carolina State University, Raleigh.

7. Elliot, A. P., Phipps, P. M., and Terrill, R. 1986. Effects of continuous cropping of resistant and susceptible cultivars on reproduction potentials of Heterodera glycines and Globodera tabacum solanacearum. J. Nematol. 18:375-379.

8. Francl, L. J., and Wrather, J. A. 1987. Effect of rotating 'Forrest' and 'Bedford' soybean on yield and soybean cyst nematode population dynamics. Crop Sci. 27:565-568.

9. Hamblen, M. L., Slack, D. A., and Riggs, R. D. 1972. Temperature effects on penetration and reproduction of soybean-cyst nematode. (Abstr.) Phyto- 
pathology 62:762.

10. Koenning, S. R. 2000. Density dependent yield of Heterodera gylicinesresistant and susceptible cultivars. J. Nematol. (Suppl.) 32:502-507

11. Koenning, S. R., Anand, S. C., and Wrather, J. A. 1988. Effect of withinfield variation in soil texture on Heterodera glycines and soybean yield. J. Nematol. 20:373-380.

12. Koening, S. R., and Barker, K. R. 1995. Soybean photosynthesis and yield as influenced by Heterodera glycines, soil type and irrigation. J. Nematol. 27:51-62.

13. Koenning, S. R., Schmitt, D. P., and Barker, K. R. 1993. Effects of cropping systems on population density of Heterodera glycines and soybean yield. Plant Dis. 77:780-786.

14. Long, J. H., and Todd, T. C. 2001. Effect of crop rotation and cultivar resistance on seed yield and the soybean cyst nematode in full-season and double-cropped soybean. Crop Sci. 41:1137-1143.

15. McCann, J., Luedders, V. D., and Dropkins, V. H. 1982. Selection and reproduction of soybean cyst nematodes on resistant soybeans. Crop Sci. 22:78-80.

16. McClean P.E, Mamidi S, McConnell M, Chikara S, and Lee R. 2010. Synteny mapping between common bean and soybean reveals extensive blocks of shared loci. BMC Genomics 11:184. doi:10.1186/1471-2164-11184

17. McLean, K. S., and Lawrence, G. W. 1995. Development of Heterodera glycines as affected by Fusarium solani, the causal agent of sudden death syndrome of soybean. J. Nematol. 27:70-77.

18. Miller, L. I. 1966. Maturation of females of Heterodera glycines as influenced by inoculum level. (Abstr.) Phytopathology 56:585.

19. Miller, L. I. 1967. Comparison of the pathogenicity and development of the Va. 2 isolate of Heterodera glycines on Pickett and Lee soybeans. (Abstr.) Phytopathology 57:647.

20. Miller, L. I. 1971. Physiologic variation within the Virginia-2 population of Heterodera glycines. (Abstr.) J. Nematol. 3:318.

21. National Agricultural Statistics Service. 2010. Agricultural Statistics Database. United States Department of Agriculture. Online publication. http://www.nass.usda.gov/QuickStats/index2.jsp

22. Niblack, T. L. 2005. Soybean cyst nematode management reconsidered. Plant Dis. 1020-1026.

23. Niblack, T. L., Arelli, P. R., Noel, G. R., Opperman, C. H., Orf., J. H., Schimtt, D. P., Shannon, J. G., and Tylka, G. L. 2002. A revised classification scheme for genetically diverse populations of Heterodera glycines. J. Nematol. 34:279-288.
24. Poromarto, S., and Nelson, B. 2009. Reproduction of soybean cyst nematode on dry bean cultivars adapted to North Dakota and northern Minnesota. Plant Dis. 93:507-511.

25. Poromarto, S., Nelson, B., and Goswami, R. S. 2010. Effect of soybean cyst nematode on growth of dry bean in the field. Plant Dis. 94:1299-1304

26. Riggs, R. D., Hamblen, M. L., and Rakes, L. 1977. Development of Heterodera glycines pathotypes as affected by soybean cultivars. J. Nematol. 9:312-318.

27. Riggs, R. D., and Schmitt, D.P. 1988. Complete characterizations of the race scheme for Heterodera glycines. J. Nematol. 20:392-395.

28. Riggs, R. D., Slack, D. A., and Hamblen, M. L. 1968. New biotypes of soybean cyst nematode. Ark. Farm Res. 17:11.

29. Ross, J. P. 1962. Physiological strains of Heterodera glycines. Plant Dis. Rep. 46:766-769.

30. Schmitt, D. P., Corbin, F. T., and Nelson, L. A. 1983. Population dynamics of Heterodera glycines and soybean response in soil treated with selected nematicides and herbicides. J. Nematol. 15:432- 437.

31. Schmitt, D. P., and Shannon. G. 1992. Differentiating soybean responses to Heterodera glycines races. Crop Sci. 32:275-277.

32. Sortland, M. E., and Mac Donald, D. H. 1987. Effect of crop and weed species on development of a Minnesota population of Heterodera glycines race 5 after one to three growing periods. Plant Dis. 71:23-27.

33. Todd, T. C., Long, Jr. J. H., and. Oakley T. R. 2003. Density-dependent multiplication and survival rates in. Heterodera glycines. J. Nematol. 35:98103

34. Todd, T. C., and Pearson, C. A. S. 1988. Establishment of Heterodera glycines in three soil types. Ann. Appl. Nematol. 2:57-60.

35. Triantaphyllou, A. C. 1975. Genetic structure of races of Heterodera glycines and inheritance of ability to reproduce on resistant soybeans. J. Nematol. 7:356-364.

36. Winstead, N. N., Skotland, C. B., and Sasser, J. N. 1955. Soybean cyst nematode in North Carolina. Plant Dis. Rep. 39:9-11.

37. Young, L. D. 1982. Reproduction of differentially selected soybean cyst nematode populations on soybean. Crop Sci. 22:385-388

38. Young, L. D. 1984. Changes in the reproduction of Heterodera glycines on different lines of Glycine max. J. Nematol. 16:304-309.

39. Young, L. D., and Hartwig, E. E. 1988. Selection pressure on soybean cyst nematode from soybean cropping sequences. Crop Sci. 28:845-847.

40. Young, L. D., Hartwig, E. E., Anand, S. C., and Widick, D. 1986. Responses of soybeans and soybean cyst nematodes to cropping sequence. Plant Dis. 70:787-791. 